\title{
MUDANÇAS NOS HÁBITOS DE SAÚDE EM TRABALHADORES DURANTE A PANDEMIA DA COVID-I9
}

\author{
Felipe Leonardo Rigo \\ Fundação Hospitalar do Estado de Minas Gerais/ FHEMIG \\ felipeleonardorigo@hotmail.com \\ Andréia Resende dos Reis \\ Hospital Eduardo de Menezes / FHEMIG \\ andreia.reis@fhemig.mg.gov.br \\ Cassidy Tavares Silva \\ Hospital Infantil João Paulo II / FHEMIG \\ tavarescassidy@gmail.com \\ Carolina Henriques Gomes Miranda \\ Hospital Infantil João Paulo II / FHEMIG \\ carolinamarialva@hotmail.com
}

\section{RESUMO}

INTRODUÇÃO: O álcool é uma substância psicoativa que pode causar dependência ao longo do tempo, e seu uso nocivo gera transtornos comportamentais e mentais, além de doenças crônicas e lesões. O cenário em virtude da pandemia pela COVID-I9 tem sido associado ao aumento do consumo de bebidas alcoólicas na população geral e estudos começam a refletir quais seriam os possíveis efeitos do álcool na saúde física e mental durante a pandemia e a longo prazo. OBJETIVO: Verificar o consumo de bebida alcoólica entre profissionais de saúde que atuaram na pandemia de COVID-19. METODOLOGIA: Estudo transversal, em um hospital referência em doenças infectocontagiosas em Minas Gerais, com I29 profissionais atuantes, no qual foi preenchido questionário sociodemográfico e Teste para Identificação de Problemas Relacionados ao uso do Álcool (AUDIT). Após a coleta os dados foram agrupados no Microsoft Excel (2016) e a análise bivariada foi realizada por meio do teste de Quiquadrado para comparar as variáveis categóricas referente ao AUDIT em relação às informações sociodemográficas. RESULTADOS: Entrevistados I29 profissionais de saúde, sendo 83,5\% mulheres, com idade entre 30 e 49 anos $(80,2 \%)$, pós-graduação $(39,1 \%)$, alocadas no centro de terapia intensiva $(34,4 \%)$ e carga horária maior que 44 horas ( $42 \%$ ). O consumo de álcool foi de 59,7\% entre os participantes e a cerveja a mais consumida (49,4\%). Na pontuação do AUDIT, o consumo de risco foi mais frequente entre os profissionais que trabalham em unidade de internação clínica, possui familiares com o hábito de consumir álcool, bebiam antes da pandemia ou que iniciaram ou tiveram aumento no consumo neste período $(\mathrm{p}<0,001)$. CONCLUSÃO: $\mathrm{O}$ estudo mostrou que o consumo de álcool é frequente entre os profissionais de saúde e houve aumento da ingestão de álcool devido ao cenário da pandemia pelo Covid-19. Sendo necessário ações institucionais direcionadas à redução do consumo nocivo de álcool.

PALAVRAS-CHAVE: Consumo de Bebidas Alcoólicas; Pandemia; Pessoal de Saúde 